\title{
Perancangan Visualisasi Tiga Dimensi (3D) Pesawat Lepas Landas
}

\author{
Ahmad Jery Ramadhan ${ }^{1}$, Ina Agustina ${ }^{2}$, M. Gufroni ${ }^{3}$ \\ ${ }^{1}$ jeryunas@gmail.com, ${ }^{2}$ ina.agustina@ civitas.unas.ac.id, ${ }^{3}$ m.gufroni@gmail.com
}

Program Studi Teknik Informatika, Fakultas Teknologi Komunikasi dan Informatika, Universitas Nasional

\begin{abstract}
This research discusses the modeling in $3 D$ from by taking the object Aerospace as the main object. Making objects Aerospace was made as easy as possible by the author using the standard 3D objects and changed shape. In modeling any added special effects to make it look more attractive. Software used for the manufacture of aircraft models are Unity 3D. it is expected that the manufacture of 3D object model aircraft will be useful for readers, especially fans of 3D model animations. Thus Modeling techniques using Unity 3D animated objects that produce smooth and highly suitable for the manufacture of organic models.
\end{abstract}

Intisari- Penelitian ini membahas pemodelan dalam bentuk 3D dengan mengambil objek pesawat terbang sebagai objek utama. Membuat benda pesawat terbang dibuat semudah mungkin oleh penulis menggunakan benda standar 3D dan berubah bentuk. Dalam pemodelan ada tambahan efek khusus agar terlihat lebih atraktif. Perangkat lunak yang digunakan untuk pembuatan model pesawat adalah Unity 3D. diharapkan pembuatan model pesawat model 3D akan bermanfaat bagi pe mbaca, terutama penggemar animasi model 3D. Dengan demikian teknik pemodelan menggunakan Unity 3D maka objek animasi yang menghasilkan kelancaran dan sangat cocok untuk pembuatan model organik.

Kata kunci-Animasi 3D, Model 3D, Unity 3D. Pesawat

\section{PENDAhUluan}

Perkembangan teknologi multimedia yang pesat berdampak pada penggunaan teknologi multimedia dalam dunia pembuatan animasi. Terdapatbeberapa jenis animasi yang sering diproduksi mu lai dari animasi $2 \mathrm{D}$ atau animasi 3D yang dibuat sedemikian rupa sehingga mempunyai sifat seperti aslinya. Model animasi 3D merupakan salah satu jenis model animasi yang masih banyak dibuat dan diproduksi hingga sekarang. Pesawat terbang merupakan salah satu hasil dari pengembangan teknologi transportasi terbaru. Pesawat terbang harus melewati udara yang labil dan berubah-ubah setiap saat dan mendadak, sehingga dibutuhkan pengontrolan yang dapat bertahan dari gangguan yang mendadak dan labil [1][2][3].

Lepas landas merupakan fase awal dalam setiap penerbangan dimana pesawat diam di runway yang kemudian diberikan suatu gaya (thrust) dari engine sehingga pesawat bergerak hingga mencapai ketinggian (screen height) tertentu. Pada fase ini yang sering dilakukan analisis adalah jarak dan waktu yang diperlukan untuk lepas landas. Jarak dan waktu tempuh saat lepas landas dipengaruhi oleh keadaan lingkungan sekitar seperti kondisi runway dan elevasi bandara. Selain kondisi sekitar, jarak lepas landas juga dipengaruhi oleh konfigurasi dari pesawat saat lepas landas seperti berat konfigurasi flap yang digunakan [5].
Dalam analisis ini pesawat dianggap sebagai suatu titik massa yang terkonsentrasi pada titik berat pesawat tersebut dimana karakteristik pesawat harus diberikan secara lengkap sebagai data informasi tersebut akan dimasukkan dalam persamaan gerak pesawat saat lepas landas [5].

Dalam penelitian ini, akan menghasilkan nilai parameter lepas landas dari pesawat terbang hingga mencapai ketinggian yang sudah ditentukan. Penelitian ini dilakukan untuk merancang lepas landas pesawat terbang (take-off) tanpa awak menggunakan software Unity 3D yang diharapkan dapat memberikan visualisasi yang baik untuk tampilan dan proses kerja pesawat. Dalam penelitian ini juga dikaji tentang bagaimana membuat model pesawat dan visualisasi pesawat lepas landas secara utuh [6][8[10[11].

\section{KAJIAN PUSTAKA}

Adapun penelitian dan desain sejenis diantaranya beberapa penelitian yang berkembang untuk lepas landas pesawat terbang adalah perancangan model pesawat diperlukan blueprint untuk arahan agar model sesuai dengan pesawat aslinya sedangkan dalam pembuatan model bandara diperlukan rancangan untuk tata letak runway, apron dan gedung terminalnya dan pada video animasi telah terdapat pergerakan pesawat dari apron menuju runway dan dari runway menuju apron terdapat sekilas tentang pengetahuan manajemen bandara [1].

Aplikasi simulasi 3D pesawat terbang dengan pengontrolan joystick dapat dengan mudah dikendalikan oleh pengguna dengan presentase sebesar $85 \%$ dan pengiriman data serial bisa dilakukan dengan software blender dengan menambahkan library serial [2][4][14].

Perangkat lunak 3Ds Max digunakan untuk merancang atau memodelkan pesawat terbang dan pemodelan pesawat terbang menggunakan pre produksi yaitu dengan membuat blueprint terlebih dahulu kemudian dilanjutkan dengan tahap produksi dengan pemodelan [3].

Gerakan dari simulasi [4][7][9][12] akan sesuai dengan variabel yang dikirimkan karena simu lasi yang dibuat terdapat sistem [13][15][16][17] yang melakukan perbandingan antara variabel yang dikirimkan pada objek serta pemakaian jenis Graphics Card yang tidak menggunakan 3D akan mempengaruhi kinerja dari simu lasi yang akan mengakibatkan pergerakan objek menjadi lambat [18][19][20].

Software Blender dapat digunakan untuk merancang model pesawat dan model 3D pesawat terbang menggunakan metode NURBS Modeling dalam proses produksinya[5].

Unity 3D merupakan sebuah game developing software yang selain bisa untuk build game PC, Unity 3D juga dapat digunakan untuk membangun game console seperti Nintendo Wii, PS3, Xbox 360, juga Ipad, Iphone dan Android. 


\section{METODE PENELITIAN}

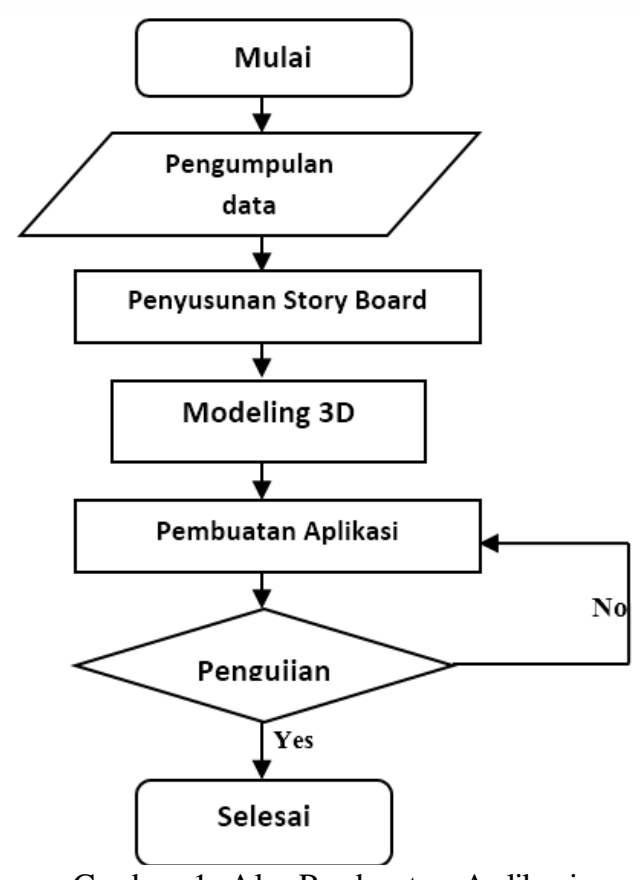

Gambar 1. Alur Pembuatan Aplikasi

Pada alur aplikasi diatas menunjukan perubahan tampilan dari satu scene ke scene lainnya dan hubungan antara satu halaman dengan halaman lainnya yang terhubung melalui garis dan tanda panah. Alur aplikasi ini dapat dilihat pada gambar 2.

\section{A. Flowchart Aplikasi}

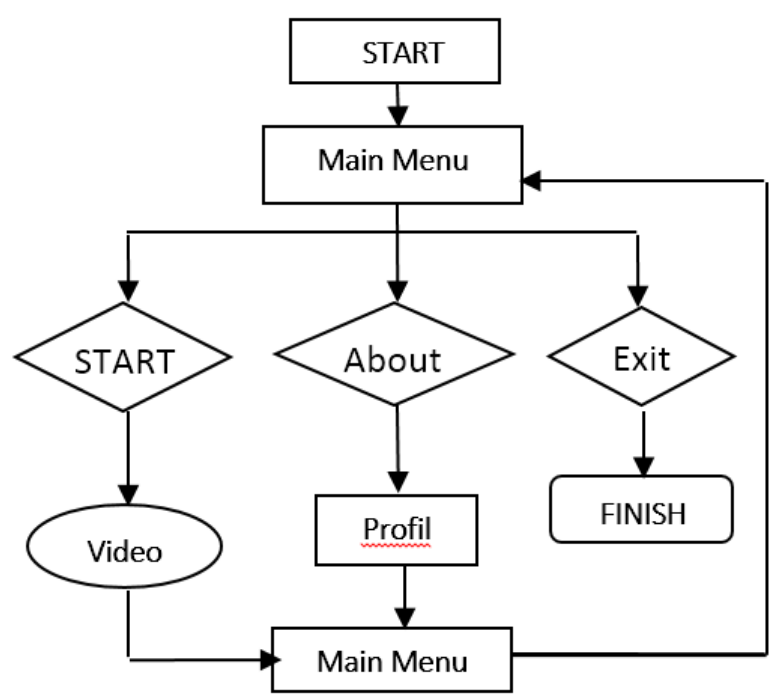

Gambar 2. Flowchart Aplikasi

\section{B. Storyboard dan Pemodelan}

Proses berikutnya yang perlu dilakukan adalah merancang visualisasi dengan Storyboard dimana dalam storyboard menjelaskan desain tampilan awal dan skenario visualisasi

Pada Tabel 1 merupakan storyboard dalam aplikasi yang berisi tampilan menu seperti menu button, play, about dan tampilan profil dari pembuat aplikasi serta keterangan mengenai pesawat terbang.
Tabel 1

Storyboard Visualisasi Pesawat Lepas Landas

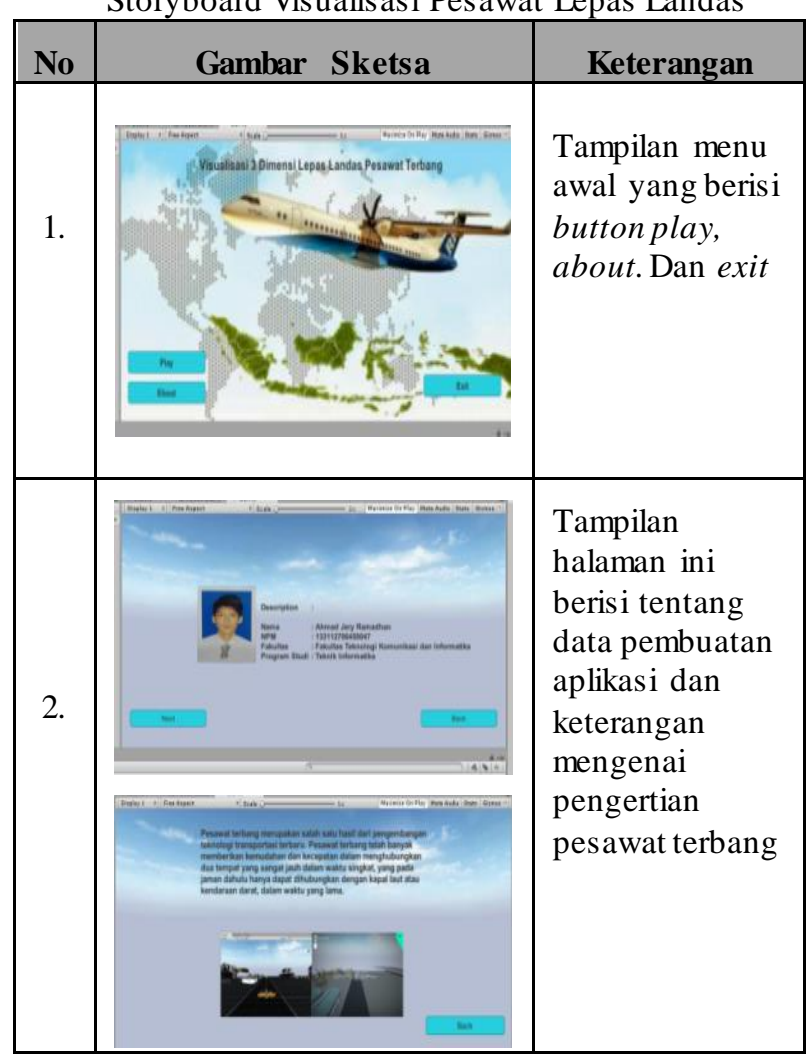

\section{Pemodelan}

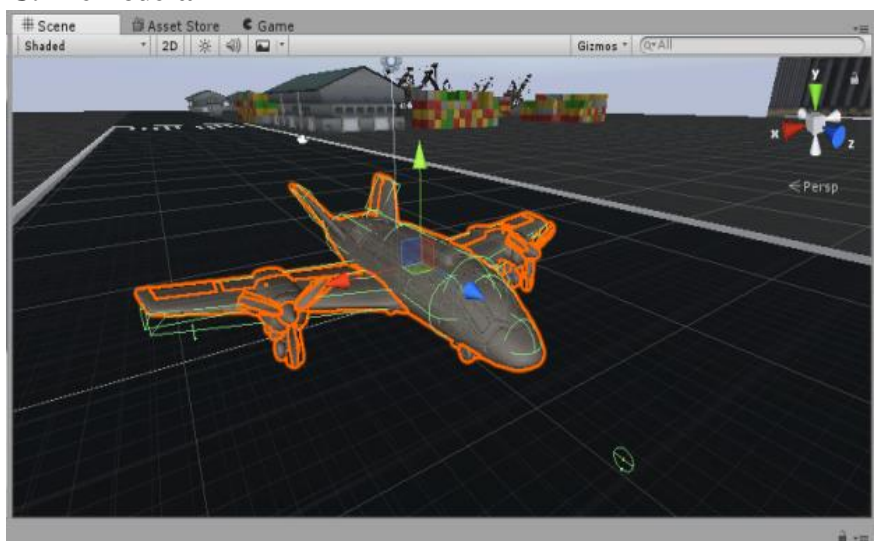

Gambar 3. Scene Pesawat Terbang

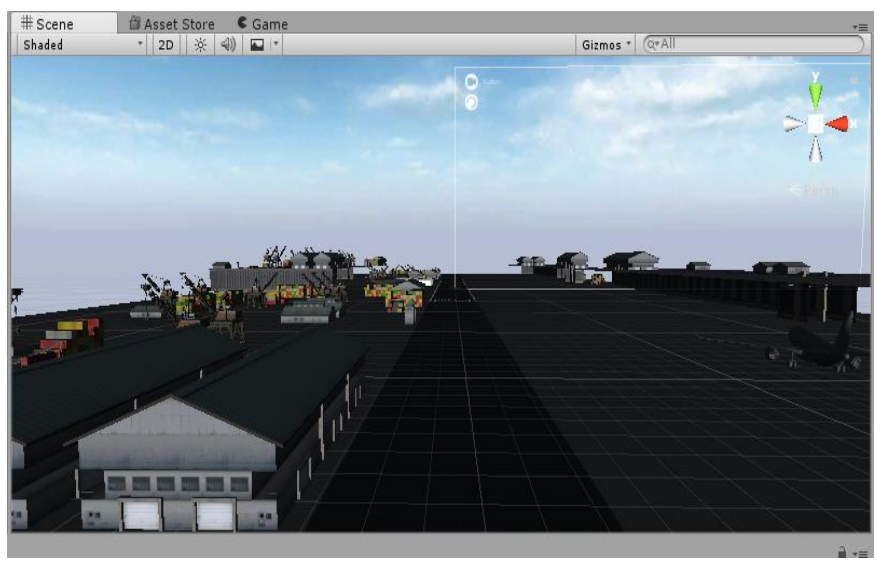

Gambar 4. Scene Model Komponen Bandara

Pada gambar 3, perancangan badan pesawat 3D dilakukan pengukuran awal terlebih dahulu dengan membentuk sebuah garis-garis serta mengatur parameter-para meter ukuran badan 
pesawat. Pada gambar 4, pada proses pembuatan model bandara ini akan dibuat perkomponen seperti membuat runway dan gedung-gedungnya.

\section{HASIL DAN PEMBAHASAN}

\begin{tabular}{|c|c|c|}
\hline Build Settings & & \\
\hline Scenes In Build & & \\
\hline$\checkmark$ Menuutama & & 0 \\
\hline$\checkmark$ myscene & & 1 \\
\hline$\checkmark$ profil & & 2 \\
\hline$\checkmark$ Informasi & & 3 \\
\hline & & Add Open Scenes \\
\hline \begin{tabular}{|l|l|} 
Platform \\
\end{tabular} & & \\
\hline A. PC, Mac \& Linux Standalone $\Theta$ & A, PC, Mac \& Lir & andalone \\
\hline 0 Android & Target Platform & Windows \\
\hline & Architecture & $x 86$ \\
\hline ios & Copy PDB files & $\square$ \\
\hline & Development Build & $\checkmark$ \\
\hline tV tros & Autoconnect Profiler & $\square$ \\
\hline & Script Debugging & $\square$ \\
\hline S5 Tizen & & \\
\hline (7) xbox One & & \\
\hline PS Vita & & \\
\hline & & Learn about Unity Cloud Build \\
\hline Switch Platform Player Settings... & & Build Build And Run \\
\hline
\end{tabular}

Gambar 5. Build Project

Pada gambar 5, proses me mbangun ke dalam platform PC, Mac dan linux standalone yaitu dengan cara file > build settings pada bagian scenes in build masukkan scene-scene yang sudah di buat dan pada bagian platform pilih PC, Mac dan linux standalone.

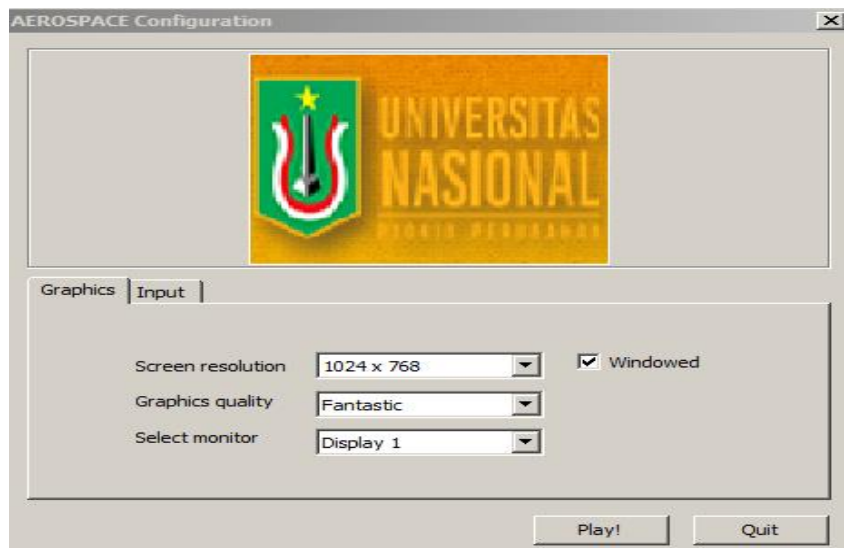

Gambar 6. Proses Rendering

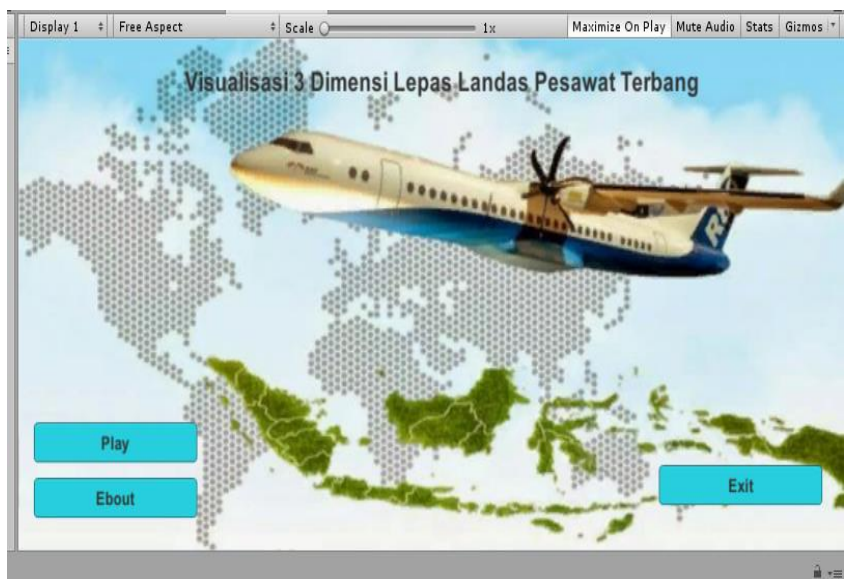

Gambar 7. Scene menu button
Pada gambar 6, tampilan ini merupakan hasil dari proses rendering yang menghasilkan tampilan yang berisi logo institusi, grafik dan input. Pada gambar 7, Untuk membuat button untuk play video judul video dijadikan button dan diberikan action script agar jika diklik video dapat play secara otomatis. Dan video di masukan ke dalam timeline dan setiap video juga diberikan action scriptplay dan stop otomatis.

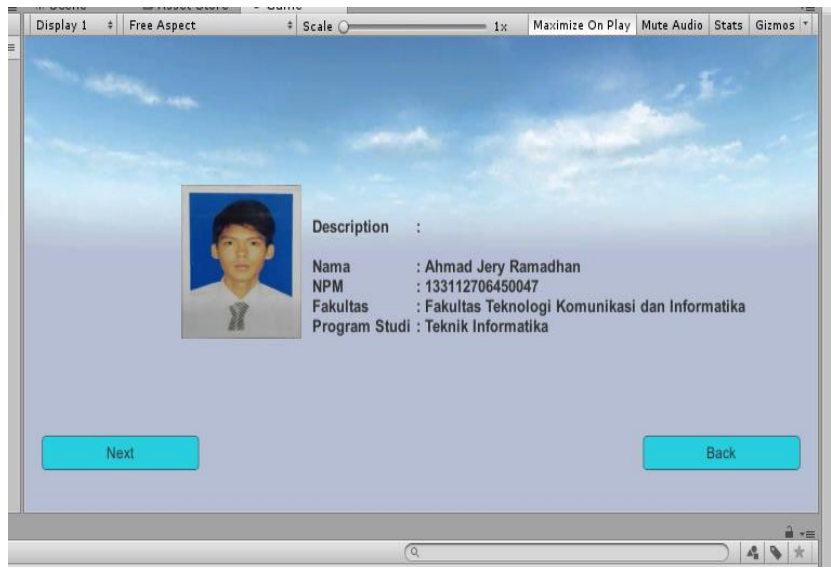

Gambar 8. Scene About

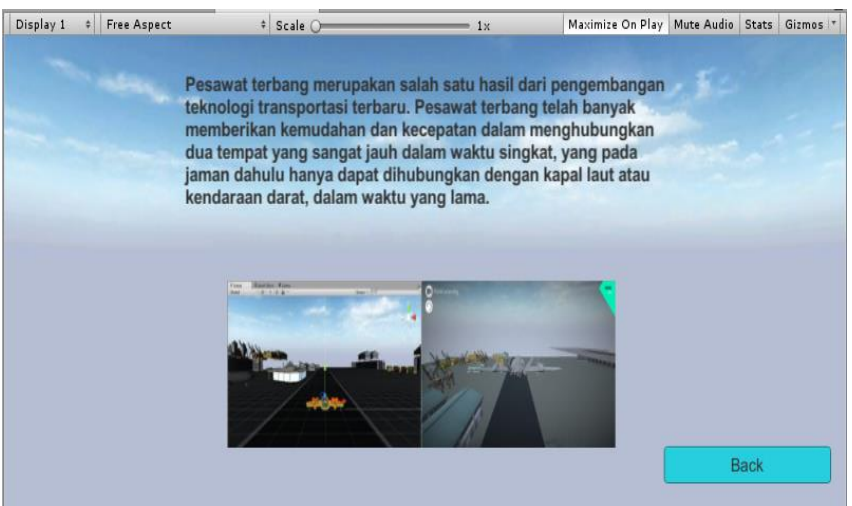

Gambar 9. Scene Tampilan Keterangan Pesawat Terbang

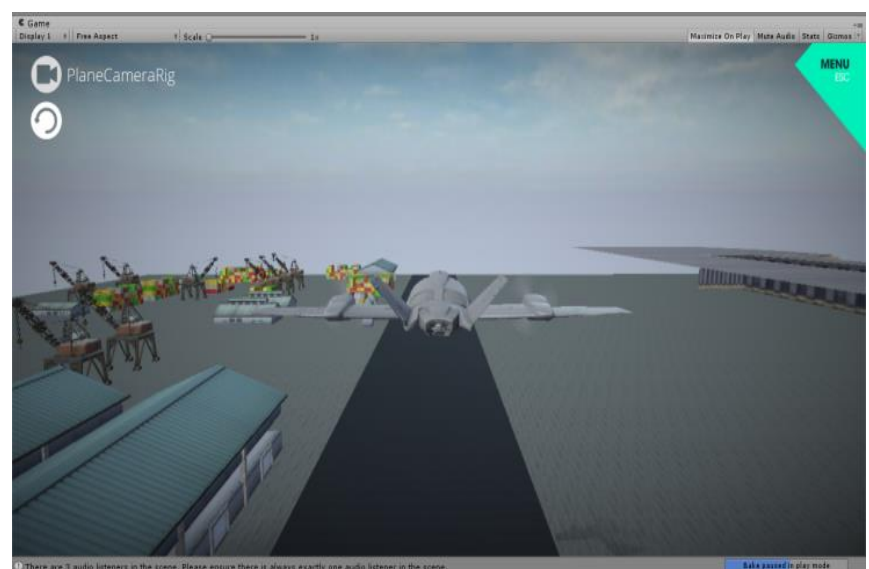

Gambar 10. Scene button play

Pada gambar 8, tampilan about ini merupakan tampilan yang berisi tentang data pembuat atau pengembang aplikasi visualisasi pesawat terbang. Pada gambar 9, tampilan ini berisi tentang informasi dan keterangan mengenai pesawat terbang. Pada gambar 10 diatas, tampilan ini berisi video mengenai lepas landas pesawat yang dimuat dari proses button play. 


\section{KESIMPULAN DAN SARAN}

Perancangan serta pembuatan pesawat terbang ini mulai dari analisis kebutuhan, implementasi serta pengujian keseluruhan dapat menghasilkan objek pesawat terbang 3D dengan pengontrolan pada pesawat terbang untuk lepas landas. Dan juga dapat memberikan edukasi yang positif sebagai media pembelajaran bagi para pilot dikarenakan tampilan akan membuat suasana pembelajaran menjadi tidak monoton.

\section{DAFTAR PUSTAKA}

[1] Nurcahyani Dewi Retnowati, Anggraini Kusumaningrum, I Made Kariada. Animasi 3D Pergerakan Pesawat pada Apron dan Runway Program Studi Teknik Informatika Sekolah Tinggi Teknologi Adisutjipto. Yogyakarta. 2016. Vol. V-1.

[2] Zulfahmi Erid inal. Meilany Dewi. Tianur. Simu lasi 3D Pesawat Terbang dengan Pengontrolan Joystick. Politeknik Caltex Riau. Pekanbaru. 2013. 211-222.

[3] Nurcahyani Dewi Retnowati. Analisis Pemodelan 3D Pesawat Terbang. Prodi Teknik Infromatika. Sekolah Tinggi Teknologi Adisutjipto. Yogyakarta. 2015. Vol. VII.

[4] Deddy Suhardiman. Rizal Sengkey. Arthur M. Rumagit. Pembuatan Simu lasi Pergerakan Objek 3D menggunakan OpenGL. Jurusan Teknik Elektro. Manado. 2010. 95515.

[5] Nurcahyani Dewi Retnowati. Supri Ermanto. Perancangan Pesawat Terbang dengan menggunakan 3D Blender. Jurusan Teknik Informatika STT Adisutjipto. Yogyakarta. 2013. Vol. V-2.

[6] Salam Aryanto. Nurcahyani Dewi Retnowati. Basir. Simulator Kendali Pesawat Terbang Extra 300 L berbasis 3D dengan metode Simulation Game. Jurusan Teknik Informatika Sekolah Tinggi Teknologi Adisutjipto. Yogyakarta. 2014. Vol. 3-1.

[7] Mulyani. Katjuk Astrowulan. Joko Susita. Autolanding pada UAV (Unmaned Aerial Vehicle) menggunakan Kontroler PID-Fuzzy. Jurusan teknik elektro. Institut Teknologi Sepuluh Nopember. Surabaya. 2012. Vol. 1-1.

[8] Asro Nasiri. Tohir Is mail. Visualis asi Navigasi Pesawat dalam Format Tiga Dimensi. STMIK Amikom. Yogyakarta. 2010. Vol. 11-1.

[9] Daniel Stojcsiscs. Andras Molnar. Autonomous Takeoff and Landing Control for Small Size Unmaned Aerial Vehicles. Obuda University. Hungaria. 2013. Vol. 32 1117-1130.

[10] MZA Rashid. MSM Aras. MA Kasim. Z. Ibrahim. A Jamali. Dynamic Mathematical Modeling and Simulation Study of Small Scale Autonomous Hovercraft. University Teknikal Malaysia Melaka. Malaysia. 2012. Vol. 46.

[11] Nilesh Kumar. Sheilza Jin. Identification, Modeling and Control of Unmaned Aerial Vehicles. YMCA University. India. 2014. Vol. 67 PP. 1-10.

[12] Atik Bintoro. Wing Support Structure LSU03 UAV Strengthen for Dynamic Load. National Institute of Aeronautics and Space. Lapan. 2016.
[13] Marian Bobe. Doru Luculescu. About the Analytical Kinematics Analysis of The Landing Gear. Air force Academy Henry Coanda.

[14] Derek Morrison. Gregory Neff. Mohammad Zahree. Aircraft Landing Gear Simulation and Analysis. American Society for Engineering Edcation. 1997. Session 1620.

[15] Christoper J. Atkinson. Development of an Aerodynamic Table Lookup System and Landing Gear Model for the Cal Poly Flight Simulator. California Polytecnic State. University. California. 2002.

[16] Navrh Podvozku Ctyrmistneho Jednomotoroveho Letouno. Landing Gear Design for Single Engine Fou Seat Aircraft. BRNO University of Technology.2014.

[17] Rue Ancelle. Landing Gear Design Loads. Advisory Group for Aerospace Research and Development. France. 1990.

[18] Yakesha Sekar, Achuthan C. Pankaj. M. Manjuprased. Reliability Studies On the Influence of Clearance on the Kinematics of the Noise Landing Gear Mechanism of a Transport Aircraft Using contact theory. National Aerospace Laboratories. India. 2016. ISSN: 1819-6608.

[19] Wei Li J.P. Fielding. Preliminary Study of Ema Landing Gear Actuation. The First Aircraft of A VIC. China. Cranfield University. United Kingdom.

[20] Rue Ancelle. The Design, Qualification and Maintenance of Vibration-Free Landing Gear. Advisory Group for Aerospace Research and Development. France. 1995. 